\title{
ARTÍCULOS
}

\section{EL PUEBLO KITU KARA: ORGANIZACIÓN COMUNITARIA, NEGOCIACIÓN CON EL GOBIERNO LOCAL Y ONTOLOGÍAS RELACIONALES*}

\author{
THE KITU KARA PEOPLE: COMMUNITY ORGANIZATION, NEGOTIATION \\ WITH LOCAL GOVERNMENT AND RELATIONAL ONTOLOGIES
}

\author{
Julián García Labrador ${ }^{1}$ \\ Facultad de Ciencias Jurídicas y Sociales. Universidad Rey Juan Carlos
}

\section{Gabriela Muñoz Vélez²}

Universidad Andina Simón Bolívar

Recibido: 29 de julio de 2019; Aprobado: 11 de mayo de 2020

Cómo citar este artículo / Citation: García Labrador, Julián y Gabriela Muñóz Vélez. 2021. «El pueblo Kitu Kara: organización comunitaria, negociación con el gobierno local y ontologías relacionales». Disparidades. Revista de Antropología 76(1): e012. doi: <https://doi.org/10.3989/dra.2021.012>.

RESUMEN: Este artículo muestra la articulación política de las comunas y comunidades indígenas constituidas como Pueblo Kitu Kara en la ciudad de Quito. Se examinan sus presupuestos identitarios como colectivo no-migrante y se explican los mecanismos organizativos que han permitido el re-descubrimiento de sus sistemas ancestrales de gobierno y la apropiación de elementos normativos constitucionales, tales como la democracia comunitaria. A través del enfoque etnográfico se explican las relaciones ontológicas entre estos sistemas ancestrales y el municipio, evidenciando las contradicciones normativas entre la constitución ecuatoriana de 2008 y la pervivencia de ordenamientos jurídicos anteriores.

PALABRAS CLAVE: Ontologías Políticas; Indígenas; Democracia Comunitaria; Comuna

ABSTRACT: This article shows the political articulation of the indigenous communes and communities constituted as Kitu Kara People in the city of Quito. It examines their identity as a non-migrant collective and explains the organizational mechanisms that have allowed the rediscovery of their ancestral systems of government and the appropriation of constitutional normative elements, such as

* El estudio presentado es resultado de la investigación Análisis de la participación política en Ecuador de los procesos ciudadanos, realizada entre los meses de abril y septiembre de 2018 en la ciudad de Quito, bajo la coordinación de la iniciativa UNOS-Grupo Faro y financiación de la Unión Europea. Agradecimiento especial a las comunas y dirigentes del Pueblo Kitu Kara por su disponibilidad y atención.

1 Correo electrónico: julian.labrador@urjc.es. ORCID iD: <https://orcid.org/0000-0001-7663-9562>.

2 Correo electrónico: gabymu5@yahoo.com.mx. ORCID iD: <https://orcid.org/0000-0002-9595-6958>. 
community democracy. The ethnographic approach explains the ontological relationships between these ancestral systems and the municipality, demonstrating the normative contradictions between the Ecuadorian constitution of 2008 and the survival of previous legal systems.

KEYWORDS: Political Ontologies; Indigenous People; Community Democracy; Commune

Copyright: (C) 2021 CSIC. Este es un artículo de acceso abierto distribuido bajo los términos de la licencia de uso y distribución Creative Commons Reconocimiento 4.0 Internacional (CC BY 4.0).

\section{INTRODUCCIÓN}

Cuando los españoles se embarcan en el proyecto conquistador y fundacional americano llevaban consigo el aparataje conceptual y normativo de la Península Ibérica. El encuentro con el indio hizo que, en primera instancia, se suscitara el debate en torno al estatuto jurídico del otro. Entre 1550 y 1551 tuvo lugar en el Colegio San Gregorio de Valladolid (España) el famoso debate o Junta de Valladolid donde se dirimía el estatuto jurídico de los indios. Conocida como polémica de naturales no pretendía debatir sobre la racionalidad de los indios o sobre si éstos eran humanos dotados de alma (asunto zanjado afirmativamente por la bula Sublimis Deus de Paulo III en 1537). Más bien trataba de justificar teológica y jurídicamente la conquista y la evangelización de la corona española. Lo que sí llama la atención en todo este asunto es que la constitución del otro tiene lugar no como relación, sino como diferencia radical, la cual aparece como «condición que nos hace conscientes de nuestros mutuos malentendidos pero no nos informa completamente acerca de las cosas que componen esos malentendidos» (De la Cadena 2015: 63).

En la Junta de Valladolid se utilizaron, por la facción favorable a los indios, los argumentos del jurista Francisco de Vitoria, quien años anteriores había defendido que los indios tenían su propia noción acerca de la propiedad y el gobierno. Además de argumentar la racionalidad de los indios, Francisco de Vitoria defendió que pudieran «ser gobernados por sus propios sistemas políticos» (Anghie 1996: 325). Sin embargo, el hecho de que las Leyes de Burgos de 1512 autorizaran el derecho de declarar la guerra sobre los indios que se resistieran a la evangelización, dio al traste con las posibilidades de entender los malentendidos.

Así, mientras en Valladolid se cerraba el debate sin una clara resolución final, en Quito se establecería poco después una estructura jurisdiccional para administrar territorios y moradores. Mediante real cédula de 29 de agosto se fundaba en 1563 la Real
Audiencia y Chancillería en la ciudad de San Francisco de Quito. Inaugurada en 1564 contaba con un presidente, cuatro oidores, un fiscal, un alguacil mayor, un teniente de gran canciller y los ministros y oficiales necesarios. La implementación española de un sistema de gobierno local sobre la ya existente organización indígena contribuyó no sólo a la invisibilización de aquellos sistemas de gobierno autóctonos que intuía Francisco de Vitoria, sino a la adaptación forzosa a una estructura política foránea, dependiente de un proyecto universal-imperial.

Quito, leal a la Corona española, se fue consolidando como referencia jurídica americana, conformando la realidad urbana según los criterios de la Real Audiencia. Hacia 1650 el cronista Diego Rodríguez Docampo refería que la ciudad merecía tal nombre haciendo una relación de las instancias de poder temporal y espiritual que acercaban la ordenación urbana a los ideales europeos (Jiménez 1965). Como indica Rosemarie Terán, «a mediados de siglo, Quito en realidad estaba provista de los elementos de su constitución formal. Una serie de símbolos la distinguían respecto del campo. Sus fronteras deseables estaban ya demarcadas» (1992: 94). Sin embargo, esta ordenación formal y simbólica, estratificada y jerárquica, no siempre encontró respuesta en los estamentos más alejados de las élites. Los grupos marginales, conformados en su mayoría por indígenas, daban al traste una y otra vez con los ideales de orden y control. La administración jurídica y territorial dependía de un concepto de autoridad colonial que entendía lo político como poder de coerción, generando tensiones y ambigüedades, toda vez que lo político no siempre había sido asociado con dicha coerción en la América Prehispánica (Clastres 2014). Por ello, como indica Kingman, las ciudades andinas «expresaron (y en parte expresan hasta el presente) las ambigüedades de esa política» (2008: 39). Las actuales relaciones de los indígenas con la ciudad de Quito manifiestan esta ambigüedad, nunca superada, pues «el mundo étnico de la ciudad no perdió su naturaleza inquietante, for- 
taleciéndose más bien como elemento perturbador por excelencia del orden social anhelado por las élites» (Terán 1992: 97). El caso del Pueblo Kitu Kara es muestra de ello.

Este artículo aborda la reactualización del sistema de gobierno ancestral del Pueblo Kitu Kara (constituido desde 2003) y sus relaciones con el municipio de Quito. El artículo se divide en tres momentos. En primera instancia se exponen las dinámicas poblacionales indígenas en la ciudad de Quito y la constitución del Pueblo Kitu Kara. En un segundo momento, se presentan los mecanismos organizativos y la estructura participativa del Pueblo Kitu Kara, profundizando en las relaciones entre las comunas y comunidades y la organización general (Congreso, Consejo y Asamblea). En la tercera y última parte se muestran las relaciones entre el Pueblo Kitu Kara y el municipio de Quito, evidenciando que las divergencias interpretativas de la normativa constitucional se fundamentan en la disimilar ontología de dos órdenes políticos en cuestión (indígena y metropolitano). Metodológicamente en nuestro estudio hemos combinado el análisis de fuentes documentales y la investigación etnográfica a través de entrevistas a líderes e intelectuales indígenas. Concluimos el estudio indicando que la reivindicación del Ayllu como forma de organización comunitaria va de la mano de la apropiación del mecanismo constitucional de la democracia comunitaria y de la inclusión de la Agenda Política del Pueblo Kitu Kara por el municipio de Quito.

\section{EL MUNICIPIO LLEGA A LAS QUEBRADAS}

Según el último censo de población y vivienda, realizado en 2010, la ciudad de Quito tiene una población de 2239191 habitantes. De ellos, el 82\% se auto-identifica como mestizo, el 6,7\% como blanco, el $4,7 \%$ como afroecuatoriano, el $4,1 \%$ como indígena y el $1,4 \%$ como montubio.

La composición de la población indígena de Quito, si bien se caracteriza por una importante migración de la sierra central y norte del país (Demon 2012; Espín 2009; Simbaña 2018), está conformada, además, por pueblos originarios previos a la conquista española. Al igual que ocurre en Bogotá (Molina 2007), La Paz (Guevara 2017) o Ciudad de México (Portal 2013) los indígenas nunca abandonaron la ciudad. No obstante, su presencia supuso un desajuste legal y administrativo para las nuevas fundaciones urbanas colo- niales, ya que el impacto de la conquista modificó el mapa poblacional originario estableciendo nuevas relaciones entre administración y territorios (Kingman 1992). Como indica Ana María Portal para el caso de la ciudad de México, «a partir de esta refundación, concentración y reacomodo de la población en lugares determinados por la corona española y la iglesia católica, muy tempranamente los pueblos fueron dotados de o les fueron restituidas porciones de tierra, en un proceso de reorganización territorial con miras a un mejor control social, tributario y evangelizador» (2013: 53). En Quito se dieron, como veremos, procesos similares.

Hablar de Quito supone referirnos geográficamente a tres espacios: la llakta ${ }^{3}$ de Quito, espacio en el que se asentó la ciudad colonial; la hoya de Quito, para indicar la región de la cuenca del río San Pedro-Guayllabamba, conocido como Quito metropolitano; y el Gran Quito, correspondiente a la extensa zona que se extiende entre las provincias de Imbabura y Chimborazo (Valarezo 1992). El Quito anterior a los incas estaba constituido por varios señoríos étnicos (Salomon 2011) que, sin una unidad política, compartían ciertos rasgos culturales en la hoya de Quito. Estos señoríos «habían creado, en el núcleo de lo que más tarde fue la ciudad en la colonia, un centro de articulación e intercambio inter-regional que desempeñaba un papel económico y de prestigio muy grande» (Valarezo 1992: 32). Los señoríos ocupaban varios espacios de la hoya de Quito, sin que pueda decirse que la llakta de Quito, futura ciudad colonial, fuera un centro habitado. Más bien correspondía a un Tianguez, término del nahualt tianquiztli, adoptado en el español americano para referirse a los mercados indígenas, cuyo control, en el caso de Quito, se disputaban los señoríos que habitaban en el exterior de la llakta.

Salomon y Grosboll (1986) identifican seis cacicazgos, argumentando diferencias sustanciales (lingüísticas, demográficas, ecológicas) entre el sur y el nor-

3 Término Kichwa para referirnos al espacio en el que se desarrolla materialmente la vida. Se suele emplear junto con el término ayllu para indicar la unidad de vida material y espiritual en un mismo lugar: "para referirse al territorio, mis abuelos y mis padres me decían que sus abuelos también les dijeron que se decía llakta; que ayllu no se refería únicamente al vínculo sanguíneo sino a la familia ampliada y a la cohesión o unidad de esos ayIlu-kuna que se desenvolvían material y espiritualmente en el ayllu Ilakta» (Pacari 2019: 155) 
te de la hoya de Quito. Así encontraríamos al sur los cacicazgos de Anan Chillo, Urin Chillo y Uyumbicho y al norte El Ynga, Puembo, Pingolquí. Esta distribución poblacional se halla confirmada no sólo por las investigaciones de uso de suelo (Knapp y Ryder 1983), sino por las referencias a los grupos étnicos nativos que encontramos en los documentos administrativos de la corona española. En efecto, en la Probanza de Don Pedro de Zámbiza (AGI, S) de 1597 aparecen diversos grupos étnicos del norte como los Quitus, Pillajos, Zámbizas y Collaguazos. Aquí encontramos una de las primeras referencias a los Quitus, en la que se apoyan los miembros del Pueblo Kitu Kara para argumentar su presencia histórica en el actual área metropolitana de Quito. No en vano, el ya citado cronista Diego Rodríguez Docampo se refiere prácticamente a los mismos grupos étnicos en el siglo XVII.

Estos grupos, habitantes de la Hoya de Quito, a pesar de su lejanía geográfica del centro de la ciudad, fueron objeto de asimilación administrativa por las autoridades coloniales. "En forma paralela a su crecimiento, la ciudad había emprendido su propia conquista del campo. En él se reprodujo a escala ampliada el "ideal urbano" a través de la multiplicación de cabildos indígenas y de parroquias eclesiásticas convertidas, como las parroquias de la ciudad, en los distritos básicos del sistema de organización del nuevo espacio colonial» (Terán 1992: 98). Este sistema organizativo se ha mantenido prácticamente inalterado hasta nuestros días, acompañado, no obstante, por resistencias, apropiaciones o resignificaciones desde los indígenas de la ciudad. Por eso, aunque nos centremos en las relaciones de los últimos años del Pueblo Kitu Kara con el municipio, muchos de sus miembros ya habían participado, como veremos, en otros movimientos sociales y organizaciones indígenas.

El Pueblo Kitu Kara se constituye de manera jurídica en 2003, aunando varias comunas y comunidades indígenas del área metropolitana. Sus líderes e intelectuales han procurado, desde entonces, presentarse como indígenas urbanos organizados políticamente frente al municipio de Quito en un proceso de esencialización identitaria de carácter estratégico (Spivak 1988, 1994). En este sentido, se apoyan en las evidencias históricas del Quito preincaico que hemos presentado y acuden tanto a las fuentes locales más fiables (González Suárez 1915; Jijón y Caa- maño 1998) como a ciertas tesis controvertidas ${ }^{4}$. Se trata de un debate histórico aún sin cerrar, del cual nos interesa más la búsqueda de modelos organizativos alternativos al municipio de Quito, que la exactitud de los datos históricos. Así, el Pueblo Kitu Kara se presenta ante el municipio de Quito no sólo como una organización más, sino como una alternativa política, históricamente fundamentada, que recoge tanto las posibles instituciones políticas preincaicas (por ello hablaremos de ontologías políticas ${ }^{5}$ ), cuanto el recorrido de resistencia de los indígenas urbanos en el Quito del siglo XX.

En efecto, la vinculación cultural de las poblaciones circundantes a Quito y su auto-reconocimiento como Pueblo Kitu Kara, ha motivado la irrupción de una agenda política propia (Pueblo Kitu Kara 2016), así como la investigación de los líderes indígenas acerca de su propia identidad en la ciudad (Tasiguano 2011). Si algunas investigaciones sobre indígenas en la ciudad en América Latina ponían el énfasis en los procesos migratorios campo-ciudad (Plata 2000; Urteaga 2007) o en el desplazamiento forzoso desde zonas militarizadas (Guevara 2004; Molina 2012), el caso del Pueblo Kitu Kara de Quito nos sitúa ante un proceso de autoafirmación política y reivindicación de paradigmas de convivencia alternativos a la territorialización llevada a cabo por el Municipio de Quito (Simbaña 2018).

Al igual que otros pueblos amerindios, los Kitu Kara entienden sus modos de organización en relación al

4 La existencia del Reino de Quito de la obra de Historia del Reino de Quito del jesuita Juan de Velasco (1789) [1927], es recogida en algunos trabajos de investigación de los miembros del Pueblo Kitu Kara, como es el caso de Ana Lucía Tasiguano, quien en su tesis de maestría (2011) trata de presentar una cohesión política organizada anterior a la llegada de los incas, cuestión que aún hoy es objeto de investigación. Aunque esta tesis puntual sea controvertida, el trabajo de Tasiguano, en general, nos parece relevante ya que recoge la experiencia contemporánea, la visión y las estrategias del Pueblo Kitu Kara en relación con el municipio de Quito. Por ello será fuente recurrente de nuestro trabajo.

5 Utilizamos ontologías políticas para referirnos a las prácticas que permiten la constitución del mundo y seguimos la definición de Annemarie Mol, inspiración para la corriente cosmopolítica (Latour, Poirier, Stengers, De la Cadena o Blaser), para quien ontología «define lo que pertenece a lo real, las condiciones de posibilidad con las que vivimos. Si el término "ontología" se combina con el de "política", entonces esto sugiere que las condiciones de posibilidad no están dadas» (Mol 1999: 75). 
territorio en el que habitan, entendido éste como un espacio de relación con los elementos de la naturaleza (figura 1) procurando una visión global del territorio:

«El territorio es el espacio de su vivencia cultural y su sustento. Es su razón de ser. Para los Quitu Cara fue y es el eje de la organización territorial y donde se fortalecen sus conceptos espirituales. Territorialmente las culturas Quitu y Cara conformaron un territorio integrado y motivado por las relaciones del maíz (Quitus), la selva y el agua (Caras). Esas relaciones marcaron su rol territorial» (Tasiguano 2011: 50).

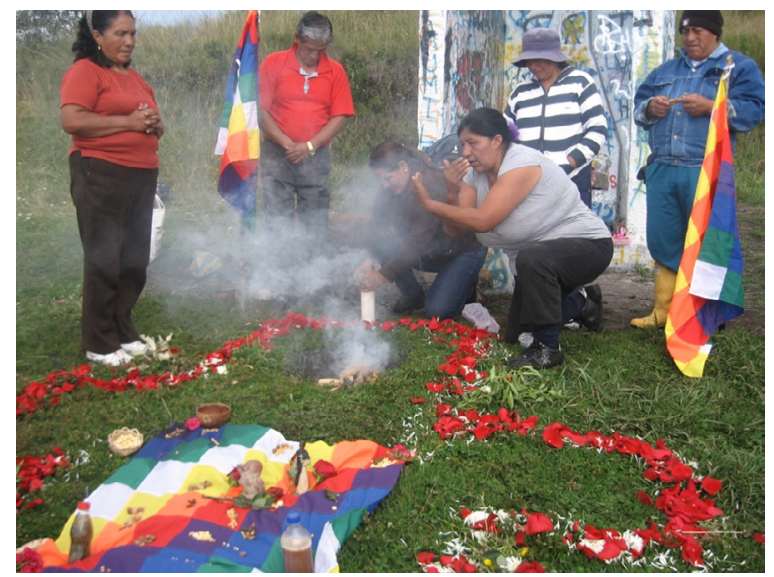

Figura 1. Ceremonia en el cerro Ungui. Comuna Chilibulo-Marcopamba-La Raya 2016. Fuente. Freddy Simbaña.

De esta manera, el Pueblo Kitu Kara reconoce que su forma de organización social se basaba en el Ayllu,

«entendido como la comunidad familiar que trabaja en forma colectiva en un territorio de propiedad común y que se fundamenta en los principios de ranti-ranti (reciprocidad), pura (integralidad), tinkuy (relacionalidad) y yanantin (complementariedad), que son la base de la identidad intercultural y la plurinacional» (Pueblo Kitu Kara 2016: 2).

La reivindicación del Ayllu contrasta con la distribución territorial llevada a cabo por el orden colonial. Con la llegada de los españoles se amalgamaron elementos prehispánicos del orden social indígena con los nuevos mecanismos de control tributario y territorial de los españoles. Así, en Quito, se permitió que los indígenas mantuvieran de manera colectiva algunas tierras de poca importancia productiva a manera de «tierra de indios, de resguardo, sobrantes, o anejos; a cambio de la prestación de servicios o el cobro de ciertos tributos»
(Andrade 2016: 18). De esta manera, los indígenas que ocupaban tierras periféricas (en muchos casos al borde de las quebradas) desempañaron labores de menor valía social y económica como limpiadores, cargadores, arrieros, albañiles, etc. En muchas comunas y comunidades esta distribución de trabajo se mantuvo durante la época republicana y se replicó con la modernización de la ciudad, profundizando la marginalización cultural, pero también la inequidad en el acceso al empleo, servicios básicos y educación de las comunidades indígenas (Carrera y Salomon 2007, Kingman 2008). Según el último censo de población y vivienda del Ecuador de 2010, los índices más elevados de analfabetismo, falta de acceso a servicios básicos, desempleo y subempleo se encuentran en las parroquias y barrios habitados por poblaciones indígenas (INEC 2010; ENEMDU 2012). En palabras de una de las comuneras de Llano Grande (figura 2), al norte de Quito:

«El alto costo de habitar en Quito ha sido el ocultamiento de nuestras formas de vida, en la capital no se consideraba que existían indígenas, se pensaba que los indígenas eran migrantes. Eso ha hecho que no exista sensibilidad, ni responsabilidad sobre esa existencia poblacional. Además, la precariedad de la vida de las poblaciones indígenas de Quito, llevó a nuestro pueblo a una especie de omisión de lo indígena para poder sobrevivir a ese espacio de la ciudad. Muchos de nuestros compañeros, de los abuelos se dedicaron a aprender y enseñar el idioma español y negar el uso de nuestro idioma. El idioma natural se lo hablaba solo en la familia íntima, afectando poco a poco nuestra identidad» (Ana Lucía Tasiguano, entrevista personal, 15 junio 2018).

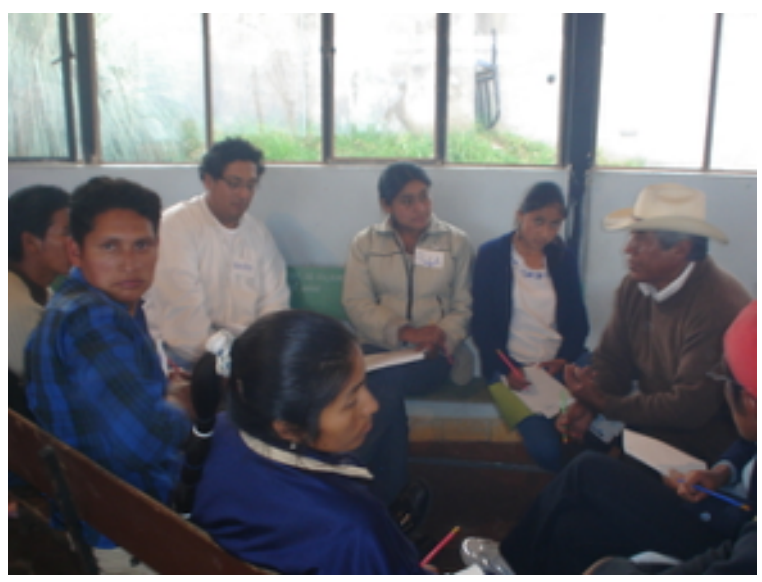

Figura 2. Comuna de Llano Grande. Reunión comunitaria previa a la constitución del Pueblo Kitu Kara. Año 2002. Fuente: Freddy Simbaña 
Los indígenas Kichwa de la Sierra ecuatoriana hicieron frente a la marginación desde varias estrategias. Por un lado, se asimilaron al campesinado en la distribución territorial de la corona española y de los gobiernos republicanos. Por eso, cuando en 1937 el estado ecuatoriano promulgó la ley de comunas muchas de las comunidades indígenas se registraron como comunas para quedar al amparo estatal. Por otro lado, la resistencia frente a la marginación se fue organizando en diversos colectivos, en los que tomaron parte algunos miembros adscritos hoy día al Pueblo Kitu Kara. En 1944 tiene lugar la creación de la Federación Ecuatoriana de Indios (FEI). En 1972 se funda la Confederación de Pueblos de la Nacionalidad Kichwa del Ecuador (ECUARUNARI) y en 1973 la Federación Pichincha Runacunapac Riccharimui. A partir de 1986, con la fundación de la Confederación de Nacionalidades Indígenas del Ecuador (CONAIE) se pone en marcha un proceso de «reconstitución de los pueblos y nacionalidades, lo que implicó, entre otras cosas, que las estructuras organizativas se establecieran de acuerdo a su identidad histórica y socio-orgánica como pueblos» (Cabascango 2019: 21). A partir de este proceso y del posterior levantamiento indígena de Ecuador en 1990, surgen las reivindicaciones por la plurinacionalidad del Estado y el derecho a la autodeterminación de los pueblos indígenas (Macas 1990).

En este contexto, las comunas y comunidades del Pueblo Kitu Kara, cuyos miembros habían tomado parte en los procesos anteriores, deciden conformar una organización política capaz de integrarlos como pueblo y generar una agenda común. En palabras de Freddy Simbaña, antropólogo y comunero de Chilibulo-Marcopamba-La Raya (figura 3$)^{6}$, a finales de los noventa, luego del levantamiento indígena, con la aprobación de la Constitución del 98 y con la creación de instancias estatales destinadas a atender las problemáticas indígenas,

«se instala con fuerza la necesidad desde la comunas y comunidades Kitu Kara de mirar hacia adentro, de identificarse con una adscripción al territorio, así como de fortalecer sus estructuras organiza-

6 Destacamos la relevancia del Dr. Freddy Simbaña Pillajo como informante, ya que se reúnen en su persona la experiencia activa como comunero y la investigación como antropólogo. Actualmente es docente investigador en la carrera de Antropología Aplicada de la Universidad Politécnica Salesiana, Quito. Agradecemos la pertinencia de sus observaciones así como el material gráfico utilizado en esta publicación. tivas y formas de gobierno comunitarias a través de elementos simbólicos y del ejercicio de sus principios ancestrales de convivencia» (Freddy Simbaña, entrevista personal, 18 junio 2018).

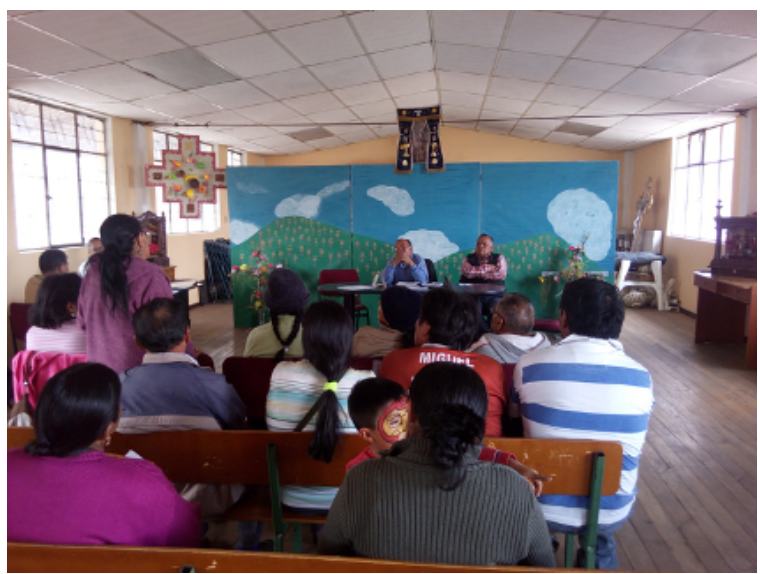

Figura 3. Asamblea comunitaria en la comuna Chilibulo-Marcopamba-La Raya en 2016. Fuente: Freddy Simbaña

En efecto, la Constitución ecuatoriana de 1998 había incorporado los derechos colectivos de los pueblos indígenas, reconociendo las formas de organización de comunas y comunidades. Sin embargo, aunque, por primera vez, se declara que Ecuador es un estado pluricultural y multiétnico, el proceder «identificando a los comuneros como campesinos y estableciendo el registro en el Ministerio de Agricultura y Ganadería» (Pueblo Kitu Kara 2016: 12) estaba en oposición a los principios de organización de las comunidades indígenas, excluyendo las nociones de autodeterminación y plurinacionalidad. Es este uno de los puntos nodales de la constitución del Pueblo Kitu Kara y eje fundamental del trabajo que presentamos: la autodeterminación del Pueblo Kitu Kara lleva consigo una reconstitución organizativa, una indagación histórica ${ }^{7}$ la puesta en valor de un sistema alternativo al municipio de Quito. «Esto inserta el debate en

7 Tal como indica Ana Lucía Tasiguano en su tesis: «Poco a poco se desvelaba una gran realidad: sus pueblos tenían un origen de mucho tiempo atrás, que había sido estratégicamente borrado de su memoria, de su lengua y de sus ojos y que su lucha por tierras, por la no discriminación, por los accesos libres al agua, toda esa fuerza tenía la raíz en la ancestralidad que le daba su identidad Quitu Cara, y que desde ese reconocimiento se trasforma en Pueblo Kitu Kara» (Tasiguano 2011: 67). 


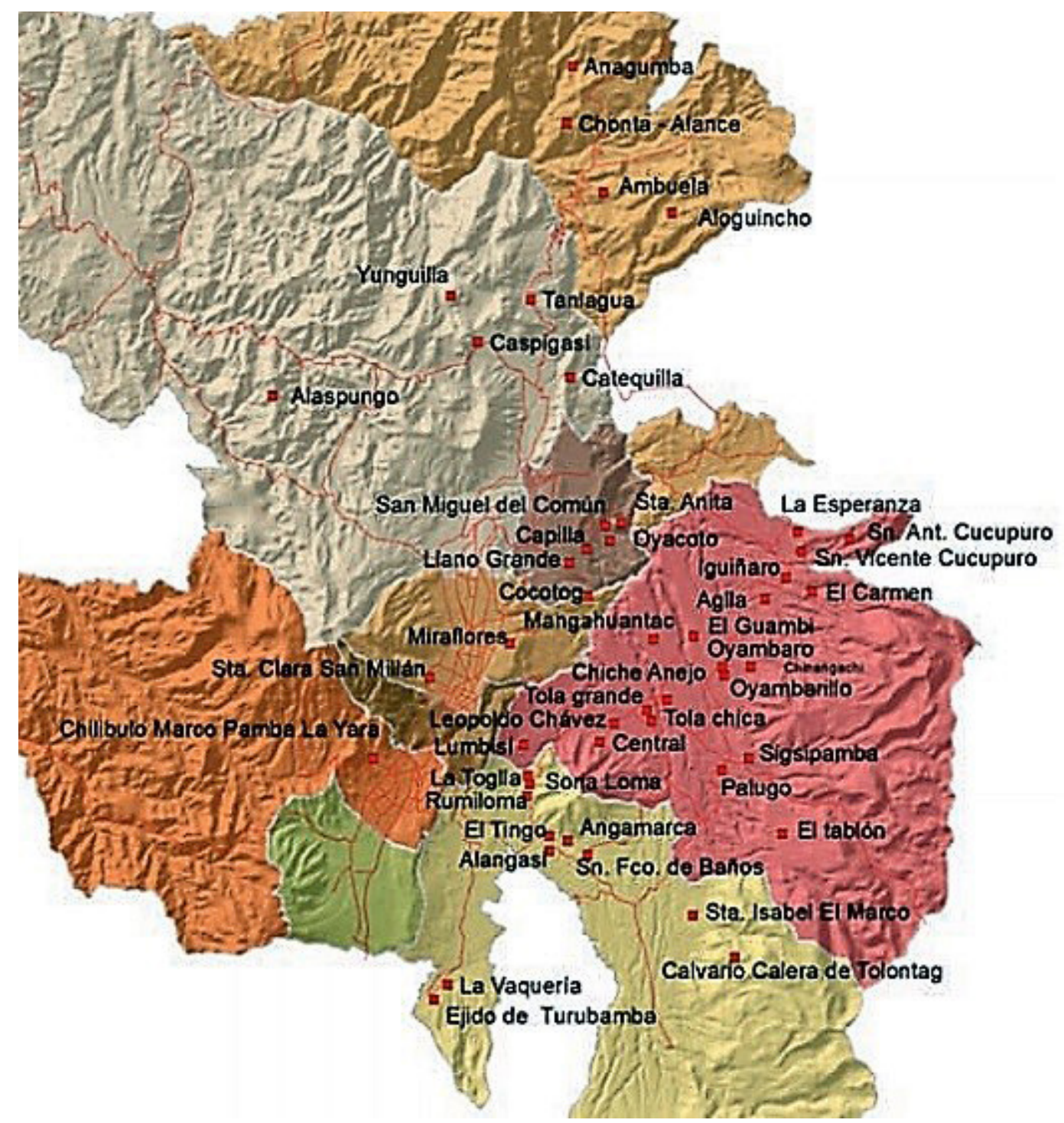

Figura 4: Ubicación actual de las comunas y comunidades del Pueblo Kitu Kara. Fuente: Agenda del Pueblo Kitu Kara 2016: 28

las agendas organizativas respecto a la autodeterminación como pueblo y nacionalidad indígena, como entidades ancestrales constituidas antes del Incario, de la conquista española y de la institucionalización del Estado Republicano» (Tasiguano 2011: 67).

El ejercicio interno del Pueblo Kitu Kara puso las bases necesarias para auto convocarse a un proceso más amplio de organización en el año 2003, generando los elementos estatuarios y declaraciones para autodefinirse como pueblo originario perteneciente a la nacionalidad kichwa y registrarse como organización territorial en el Consejo de Desarrollo de las Nacionalidades y Pueblos del Ecuador (CODENPE), adscrita a las ya mencionadas ECUARUNARI y CONAIE. En la actualidad el Pueblo Kitu Kara es una autoridad territorial de derecho comunitario, parte de los 18 pueblos y 14 nacionalidades del Estado ecuatoriano (Pueblo Kitu Kara 2016). Está integrado por aproximadamente noventa comunas y comunidades ubicadas en las parroquias rurales y urbanas del cantón Quito y en algunas parroquias rurales de los cantones Rumiñahui y Mejía ${ }^{8}$ (figura 4). Cabe mencionar que no todas las comunas

8 De ellas, solo 22 se encuentran registradas en el inventario del Municipio del Distrito Metropolitano de Quito como comunas y comunidades ancestrales. 
tienen adscripción territorial o autodeterminación como comunas o comunidades del Pueblo Kitu Kara. Algunas de ellas solo se reconocen como «pueblos de campesinos-agricultores» (Pueblo Kitu Kara 2016: 12). Es este el principal desafío al interior del proceso organizativo, ya que la ley de comunas de 1937 (aún vigente) entra en colisión con el reconocimiento de los derechos de autodeterminación de la constitución de 2008 que, además de declarar a Ecuador como un estado «intercultural, plurinacional y laico» (art. 1), reconoce, en el cap. IV, los derechos de comunidades, pueblos y nacionalidades a la propia organización y al territorio ancestral (art. 57). Así, en sus relaciones con el municipio de Quito, el Pueblo Kitu Kara parte de figuras como el Ayllu y el Consejo de Gobierno para hacer efectivos los derechos colectivos. Además, a partir de su propia experiencia, interpreta la democracia comunitaria, reconocida en los artículos 57 y 95 de la constitución, como una declaración política de la organización indígena comunitaria. Sin embargo, la puesta en juego de estas formas de gobierno choca con la agenda municipal, evidenciando que los malentendidos y tensiones se deben a diferentes formas de constitución del mundo. Para el Pueblo Kitu Kara sus procesos organizativos aparecen como «ontologías relacionales» (Poirier 2008: 77), según las cuales, la realidad política no es tanto la aplicación de una distribución preestablecida cuanto el resultado de «vivencias e interacciones concretas» (Poirier 2008: 77).

\section{EN COMUNA. MECANISMOS ORGANIZATIVOS Y ONTOLOGÍA DEL PUEBLO KITU KARA}

La estructura organizativa del Pueblo Kitu Kara está conformada por tres espacios: los congresos, las asambleas y las reuniones permanentes del Consejo de Gobierno. Según Fernando Cabascango, presidente del Consejo de Gobierno, estos mecanismos «buscan asegurar la participación plena de las comunas y comunidades en la construcción de propuestas, proyectos, en la toma de decisiones y en la corresponsabilidad para llevar a cabo su incidencia» (Fernando Cabascango, entrevista personal, 16 julio 2018). Así tenemos:

«El Congreso, espacio donde se definen los lineamientos y el mandato del Pueblo Kitu Kara. Se reúne cada tres años ordinariamente para elegir al Consejo de Gobierno y, extraordinariamente, cuantas veces sea necesario para tratar temas puntuales como reformas de estatuto o generación de normativas que ayuden al fortalecimiento de las comunas o comu- nidades. Del mandato que el Congreso transfiere al Consejo deriva la Agenda Política del Pueblo Kitu Kara. En este sentido, nos interesa señalar la estructura interna y el dinamismo de los órganos de representación del Pueblo Kitu Kara. En el Congreso participan cinco delegados de cada comuna o comunidad, quienes tienen voz y voto en la toma de decisiones. Pueden participar las personas que deseen, pero solo con derecho a voz. Estos cinco delegados son designados por cada comuna o comunidad. Para ello, se invita a los cabildos (comunas) o consejos de gobierno (comunidades) para que envíen la nómina de los delegados oficiales y fraternos.

Además del Congreso, la Asamblea, conformada por los presidentes de las comunas y comunidades y el Consejo de Gobierno del pueblo Kitu Kara, son las instancias para la toma de decisiones, resoluciones y ejecución del plan o programa de gobierno del Pueblo Kitu Kara».

Descubrimos así dos niveles de representación. El nivel de representación de autoridades (Asamblea) y el nivel de representación delegativa (Congreso). Teniendo en cuenta que el mandato para el órgano directivo (Consejo) proviene del nivel delegativo (Congreso), creemos necesario ahondar en las dimensiones del Consejo de Gobierno del Pueblo Kitu Kara para establecer su alcance político y los términos de sus relaciones con el municipio de Quito.

El Consejo de Gobierno como órgano de representación está conformado por siete dirigencias: Presidencia, Vicepresidencia, Fortalecimiento Organizativo, Tierras y Territorios, Mujer, Jóvenes y Comunicación. Todos los miembros tienen poder de decisión en condiciones de igualdad. Cada dirigencia cuenta, además, con la posibilidad de plantear sus planes dentro del Plan General que tiene el Pueblo Kitu Kara. Esta forma de organización garantiza la horizontalidad en la generación de propuestas y toma de decisiones. En este sentido, Ana Lucía Tasiguano indica que, al elegir al Consejo de Gobierno, se busca garantizar la representatividad territorial: «La primera característica del gobierno es que haya representatividad de todas las zonas, que cubran zonas estratégicas urbanas y rurales, y de esa manera poder generar criterios que respondan a realidades diferentes porque nuestra lucha está ligada al territorio» (Ana Lucía Tasiguano, entrevista personal, 15 junio 2018).

Según Fernando Cabascango:

«El presidente del Consejo de Gobierno ejerce la representación legal de Pueblo Kitu Kara, así como la responsabilidad de velar por el cumplimiento del 
mandato, la Agenda Política y los diálogos con otros actores (acompañado siempre de las dirigencias que manejan las temáticas específicas). Por otra parte, el vicepresidente tiene la responsabilidad de la coordinación y seguimiento a los proyectos del Pueblo Kitu Kara. El Consejo cuenta además con un nivel de apoyo técnico externo para temas puntuales. El Consejo de Gobierno se reúne cada semana para hacer una planificación e informar los avances de los planes y programas emitiendo, además, informes semestralmente de los avances del mandato del Pueblo Kitu Kara». (Fernando Cabascango, entrevista personal, 16 julio 2018)

Fernando Cabascango añade que esta estructura y forma de gobierno es radicalmente diferente a las formas de gobierno tradicionales, donde la autoridad plantea la propuesta y ejerce la autoridad. Con ello se está refiriendo a las formas en las que la corona española y los gobiernos republicanos habían concebido los órganos de representación indígenas y su relación con el territorio. Nos referimos al cabildo. El «cabildo, conformado por miembros de la comunidad, dividido en cargos jerárquicos, de los cuales los más comunes son: gobernador, alcalde, alguacil, tesorero, secretario y una guardia indígena» (Vera 2015: 32) pretendía dotar a las comunidades indígenas de cierta estructura política inteligible para los funcionarios españoles, anticipando lo que Scott (1998) descubriría para la posterior territorialización del Estado moderno. Con la llegada de los gobiernos republicanos el cabildo fue configurándose como la entidad mediadora entre el estado y los indígenas, conformando una relación asimétrica entre la estructura jerárquica del cabildo y las formas comunitarias indígenas - para algunos autores el cabildo urbano ha contribuido a la deslegitimación de los grupos indígenas (Vera 2015) -. Por eso, el Pueblo Kitu Kara pretende superar la distribución asimétrica del cabildo a través de la democracia comunitaria.

Para Arturo Escobar $(2010,2015)$ la colonización se inscribe en el proyecto moderno que ha fragmentado la realidad, haciendo de ella un conjunto compartimentado en que la política y el capital asignan lugares y espacios. Así, el cabildo actual (aún en vigencia) al que se refería Fernando Cabascango, corresponde, desde el punto de vista organizativo, con presidente, vicepresidente, secretario, síndico y tesorero y, desde el punto de vista territorial, con una visión de la tierra en términos de propiedad privada. De esta manera, el cabildo cierra el espacio para «una manera diferente de imaginar la vida (mundos 'socio-naturales')» (Escobar 2010: 4). En efecto, la filosofía política de la conquista española estaba sustentada por la Escuela de Salamanca que, fundándose en el tomismo, consideraba el ordenamiento de la realidad como la tarea política fundamental. Así por ejemplo, el Real Poder para dar entera libertad a los indios que hubieren capacidad de vivir por sí ordenadamente de 1518 establecía que «podrán vivir por sí política y ordenadamente en pueblos» (Konetzke 1953: 69). Si algo ofrecía el cabildo era la posibilidad de ordenar poblaciones.

En la crítica a la figura del cabildo, el Pueblo Kitu Kara indaga, por un lado, sobre las formas de organización prehispánicas y, por otro, descubre las contradicciones jurídicas del articulado ecuatoriano en torno a la organización política, apropiándose críticamente de algunos mecanismos (democracia comunitaria) y distanciándose de otros (cabildos).

En la recuperación de las instituciones prehispánicas, el Pueblo Kitu Kara reconoce e integra las formas de organización comunitaria (Ay/lu) y las figuras de autoridad ancestrales (Varayuc). El Ayllu, es una forma de organización territorial, cultural, de parentesco, etc. (Rivera Cusicanqui 1990; Yampara 2001; Pacari 2019) que se comprende como célula indivisible e interrelacionada. Comunidad y Ayllu pasaron a ser sinónimos desde el siglo XIX. La Agenda Política del Pueblo Kitu Kara reconoce los 4 principios del Ayllu-comunidad (reciprocidad, integralidad, relacionalidad, complementariedad) como base de la interculturalidad y la plurinacionalidad y con ello está vinculando la ancestralidad organizativa con el art. 1 de la constitución de 2008, que reconoce un Estado intercultural y plurinacional. Además, como forma de autoridad ancestral, los varayucs eran una figura política cuya razón de ser estribaba en la capacidad de discernir sobre asuntos comunitarios. En Perú, bajo el nombre de varayocs, se los consideraba uno de los cargos imprescindibles en los rituales andinos junto con "altamisayocs, paqos, pasantes, devotos, etc.» (Celestino 1998: 12). Como indica Quijada Jara (1981) los varayocs eran una autoridad de orden político ritual y moral. También para los Kitu Kara «en el mundo indígena los varayucs eran los sabios que tenían la potestad de tomar decisiones. Este rol se precariza en la colonia con los cabildos que los transforma en mediadores de las autoridades» (Ana Lucía Tasiguano, entrevista personal, 15 junio 2018). En la actualidad el Pueblo Kitu Kara reconoce el papel de los varayucs en el acercamiento a los ancianos de las comunidades y en la entrega del bastón de mando. 
La recuperación / implementación de estas formas ancestrales de organización va de la mano de la integración con el articulado jurídico ecuatoriano. Así, lejos de la idealización romántica, el Pueblo Kitu Kara desarrolla lo que la Constitución de 2008 señala a propósito de la participación ciudadana: «la participación de la ciudadanía en todos los asuntos de interés público es un derecho, que se ejercerá a través de los mecanismos de la democracia representativa, directa y comunitaria» (art. 95).

Amparándose en la democracia comunitaria el Pueblo Kitu Kara reivindica la práctica de lo comunitario en el ejercicio organizativo, participativo y político. "La democracia comunitaria de las nacionalidades y pueblos se sustentan en las asambleas generales y comunitarias para resolver o adoptar decisiones. En estos espacios se desarrollan discusiones y diálogos con la intervención directa de la población con presencia intergeneracional y de la mujer» (Ana Lucía Tasiguano, Foro Universidad Andina Simón Bolivar, Quito, 19 abril 2018). Por eso, son las comunas y las comunidades quienes plantean los mandatos y construyen colectivamente la Agenda Política que deberá ejecutar el Consejo de Gobierno. Y es, precisamente este ejercicio comunitario el que liga la organización del Pueblo Kitu Kara con la cuestión territorial, asimilando la democracia comunitaria con la propiedad comunitaria.

Al igual que en otros lugares del continente americano «las autoridades indígenas, en todo escenario, coinciden en que la lucha por recuperar territorios y derechos es la constante y la razón de la pervivencia de los pueblos indígenas» (Vera 2015: 34). Es este un aspecto clave en la relación del Pueblo Kitu Kara con el municipio de Quito.

Por un lado, los territorios ancestrales se limitaban por hitos naturales no siempre susceptibles de ser definidos con precisión, lo que ha mermado la titulación jurídica y el registro de la propiedad ancestral. Por otro lado, a pesar de que el artículo 14 del Convenio 169 de la Organización Internacional del Trabajo sobre Pueblos Indígenas y Tribales en Países Independientes establece que «deberá reconocerse a los pueblos interesados el derecho de propiedad y de posesión sobre las tierras que tradicionalmente ocupan [...]», no existe aún una ordenanza municipal que permita tal reconocimiento de las tierras tradicionalmente comunales. La posesión de la tierra aún depende de su titulación como propiedad individual. Como indica la
Organización de los Estados Americanos (2014) «existen en el Ecuador algunas barreras legales al goce pleno y efectivo del derecho a la titulación del territorio ancestral debido a que el Código Civil establece que se requiere de un título registrado para probar la propiedad de la tierra». Por eso, Javier Andrade indica que los territorios ancestrales de Quito

«históricamente han estado excluidos de los modelos de gestión territorial por reunir unas características distintas al modelo de propiedad individual. Esta exclusión se evidencia en la falta de un cuerpo jurídico normativo en la jurisdicción del Distrito Metropolitano de Quito que establezca criterios sobre la aplicación del Derecho Urbanístico en las comunas ancestrales». (2016: 4).

Los derechos de las comunidades indígenas al territorio han sido reconocidos por la Corte Interamericana de Derechos Humanos en varios casos (Comunidad Mayagna Sumo Awas Tingni vs. Nicaragua en 2001; Sawhoyamasca vs. Paraguay en 2006). La Constitución de 2008 del Ecuador y el posterior proyecto normativo estatal han intentado aplicar este reconocimiento. Así el art.6 del proyecto de Ley de Tierras y Territorios de 2012 establecía por primera vez la propiedad comunitaria:

«tierras adquiridas en común para beneficio de un colectivo social, con un único título de propiedad que resguarda el interés común, y cuyo aprovechamiento puede ser familiar o colectivo; y los territorios de pueblos y nacionalidades. Es decir, los espacios ancestralmente ocupados por los pueblos o nacionalidades indígenas, afro ecuatorianas y montubias, que sintetizan los elementos básicos de la identidad, donde hay condiciones de producción y reproducción social y cultural».

Sin embargo, el posterior articulado relativo a la propiedad comunitaria se ha remitido a las áreas rurales. La Ley Orgánica de Tierras Rurales y Territorios Ancestrales de 2016 indica que la propiedad comunitaria es «la que ha sido adjudicada y titulada en favor de comunas, comunidades, pueblos y nacionalidades» (art. 85). Esta propiedad es «imprescriptible, inalienable, inembargable e indivisible y estará exenta del pago de tasas e impuestos» (art.23).

En este sentido, descubrimos algunas contradicciones normativas entre el articulado estatal y las disposiciones del Distrito Metropolitano de Quito, que explican la crítica del Pueblo Kitu Kara a la normati- 
va vigente, estableciendo los vínculos que la ley no aplica entre democracia comunitaria y propiedad comunitaria. En primer lugar, a pesar de que el Estado ecuatoriano reconoce la figura legal de la propiedad comunitaria, falta la ordenanza municipal que haga efectivo su reconocimiento legal en las comunas de Quito. Así, el Art. 8 de la Ordenanza Metropolitana que aprueba el Plan de Ordenamiento Territorial del Distrito Metropolitano de Quito (2012) distingue en sus numerales a) y b) entre suelo urbano y suelo rural. El suelo urbano es objeto de ordenamiento urbanístico, mientras que el suelo rural, limitado a usos agropecuarios o paisajísticos, no puede ser adscrito a la categoría anterior. ¿Dónde queda la propiedad comunitaria? En segundo lugar, la Ley de Organización y Régimen de Comunas de 1937, (vigente hasta la actualidad, con una codificación en 2004), si bien reconoce formalmente las comunas, no permite recuperar las formas de organización y gobierno ancestrales, al mantener una estructura de cabildo tradicional y una visión de posesión de la tierra anclada en la propiedad privada y la productividad. «El sentido comunal que se mantiene en esta ley responde más bien al modelo colonial y al carácter productivo de la tierra, antes que a los principios de lo colectivo y comunitario» (Ana Lucía Tasiguano, entrevista personal, 15 junio 2018).

Estas contradicciones urbanas han llevado a las comunas y comunidades a plantear la necesidad de estructuras que les permitan ejercer sus derechos de autodeterminación y así recuperar sus prácticas ancestrales comunitarias de gobierno. Si bien las comunas del Pueblo Kitu Kara se rigen por la Ley de Comunas, anteriormente citada, y el cabildo como figura de organización, se procura que las decisiones del cabildo partan de los principios de lo comunitario. Algunas comunas han optado por abandonar la figura de comuna para constituirse como comunidades de origen ancestral y así declararse como un gobierno comunitario territorial (registrado ante el entonces Consejo de Desarrollo de las Nacionalidades y Pueblos del Ecuador - CODENPE) para ejercer la figura del Consejo de Gobierno y sus principios comunitarios. De esta manera dejan atrás la figura representativa administrativa del cabildo que, al igual que en el caso colombiano (Vera 2012), impedía una legitimación de los colectivos indígenas en la ciudad. Es el caso de la comunidad la Toglla (figura 5), que en 2005 hizo la transición para convertirse en comunidad de origen ancestral y registrarse ante el CODENPE, tal como nos relató su presidente Jaime Paucar (entrevista personal, 13 julio 2018).

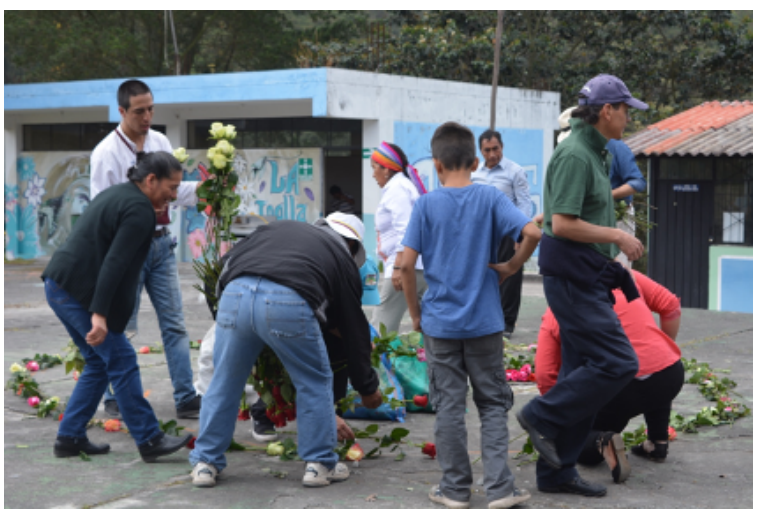

Figura 5. Comunidad de la Toglla. Preparación de la Pambamesa. Celebración del Inti Raymi de 2018. Fuente: Julián García

La transición del Cabildo al Consejo de Gobierno en cada comunidad viene de la mano de las contradicciones en la legislación territorial que veíamos con anterioridad, así como de la necesidad de recuperación de las figuras de organización ancestrales. Como indica Ana Lucía Tasiguano: «No podemos tener un cabildo sin un territorio y tampoco el territorio sin una visión o autoridad central. Lo central es el espacio en donde ellos o ellas delinean nuestras causas de vida» (Ana Lucía Tasiguano, entrevista personal, 15 junio 2018).

El proceso organizativo del Pueblo Kitu Kara se ha desarrollado, por eso, en varios niveles. (i) Desde las comunas y comunidades, recupera sus formas de gobierno y la toma de decisiones. (ii) A través de la Organización del Pueblo Kitu Kara y su definición como autoridad ancestral territorial, construye y adopta decisiones de forma horizontal, con la participación directa de las comunas y comunidades, bajo los principios de lo comunitario. (iii) El tercer nivel apunta a las políticas públicas para que se hagan efectivos los derechos a la autodeterminación, a la consulta previa, libre e informada, a la propiedad comunitaria, a la conservación y el desarrollo de sus propias formas de convivencia y organización social, de generación y ejercicio de la autoridad, así como el ejercicio de las funciones jurisdiccionales reconocidas en la Constitución. Este último nivel nos parece fundamental para apreciar la contribución de la organización comunitaria del Pueblo Kitu Kara. Como indica Jaime Paucar, presidente de la comunidad de la Toglla: 
«El espacio para gobernar colectivamente, para pensar en el bienestar común está ligado a lo comunitario. Este ejercicio va más allá de lo conceptual, es un ejercicio práctico y ese es uno de los esfuerzos que está haciendo el Pueblo Kitu Kara: repensar lo comunitario no solo para el beneficio de las comunidades, sino lo comunitario como una práctica de vida para la sociedad ecuatoriana en su conjunto». (Jaime Paucar, entrevista personal, 13 julio 2018)

\section{ONTOLOGÍAS, AGENDAS Y MUNICIPALIDAD}

La territorialización de la ciudad de Quito por la corona española supuso, como vimos en el primer apartado, la partición, la asignación de espacios y la reorganización de los indígenas para un mejor control de la fuerza de trabajo y de la distribución de tributos. Dicha territorialización se enmarca en el proceso expansivo de la modernidad europea que impuso arbitrariamente un conjunto de separaciones y diferencias (Bigo y Walker 2007) sobre territorios y poblaciones. Las ordenanzas municipales del Quito del siglo XXI no se alejan de este esquema al distinguir de manera irreconciliable el suelo urbano y el suelo rural. El proyecto político de la modernidad se basa, precisamente en distinciones: la distinción entre humanos y no humanos (De la Cadena 2015), la distinción entre moderno y no-moderno (Latour 1993) y la asunción de una línea temporal progresiva que distingue entre el atraso y el progreso (Rojas 2016). Estas distinciones han provocado que la incorporación de los indígenas a las ciudades se realice desde el presupuesto modernizador, como si hubiera llegado el turno de que ya tuvieran su lugar en el progreso de la ciudad, como pone de manifiesto Nadia Guevara (2017) en el caso de La Paz.

El hecho de aplicar diferencias y establecer distinciones desempeña una clara función política ya que, por una parte, aparece la instancia que determina cómo distribuir los espacios y, por otra, se eliminan los posibles puntos ciegos de la realidad para quien epistémicamente asume un único modelo de conocimiento. Como indica Sanjay Seth (2013), si antes estábamos ciegos, ahora podemos ver. De igual manera James Scott alude a esta cuestión al indicar que la territorialización administrativa de los estados modernos responde a la necesidad de que la burocracia estatal pudiera escapar del «punto parcialmente ciego» (1998: 2) que ofrece una realidad sin cuantificar.

Sin embargo, aunque las líneas de investigación académicas del grupo MCD y del llamado giro onto- lógico ${ }^{9}$ traten de delimitar este proceder en el marco de la modernidad y así presentarlo como una determinada ontología política entre otras (Blaser 2013), los postulados epistémicos de las políticas públicas de Quito en los últimos años parecen no haber abandonado este paradigma. Sin ir más lejos, en el Foro Experiencias de Democracia Comunitaria en Ecuador celebrado en la Universidad Andina Simón Bolívar de Quito el 19 abril de 2018, Luis Verdezoto, conocido sociólogo y catedrático de la ciudad, se refirió a la democracia comunitaria en la Constitución ecuatoriana de 2008 como inclusión de elementos étnicos en el articulado constitucional, objetualizando las ontologías otras, reduciendo su riqueza relacional, semántica, vital, etc. a una representación de la misma (Rojas 2002; Blaser 2010). Por ello, como afirman Icaza y Vázquez (2013), las luchas sociales por la justicia son también las luchas contra la deslegitimación epistémica. En este sentido, también se manifestó Ana Lucía Tasiguano, participante del mismo Foro del 19 de abril, indicando que

\begin{abstract}
"la sola interpretación de que el Sumak Kawsay es vivir bien aceleró las mismas proyecciones de ese desarrollo que reafirmó los modelos hegemónicos, irresponsablemente extractivistas y desde políticas pensadas desde los superior/centro estatal, dejando de lado los sistemas locales y menos aun considerando a lo comunitario».
\end{abstract}

Lo que está indicando Tasiguano se comprende mejor desde el descubrimiento de una ontología propia que determina y alimenta lo que los Kitu Kara entienden por política. Rivera Cusicanqui (1987) ha indicado que en los andes bolivianos no pudo ejecutarse la revolución marxista en el sentido que esperaban los intelectuales. Realizar esa revolución implicaba convertir las comunidades indígenas en comunidades campesinas, para, de este modo, entender la lógica revolucionaria en la ontología política marxista y su visión de la historia. El marxismo, siguiendo la lógica hegeliana, entendía «la diferencia como mediación» (Biset 2011: 12) sin advertir que, con ello, estaba cerrando la diferencia en la ontología de la totalidad del proceso. Por

9 El grupo Modernidad, Colonialidad, De-colonialidad estaría formado entre otros por Katherine Walsh, Walter Mignolo Edgardo Lander, Fernando Coronil, etc. El paradigma ontológico de la antropología contaría, entre otros, con Viveiros de Castro, Philippe Descola, Martin Holbraad, Marilyn Strathern, Roy Wagner, Eduardo Kohn, etc. 
ello, la revolución marxista requería de la diferencia del campesinado como un momento del proceso total. De igual modo, las distinciones jerárquicas de la modernidad que hemos visto en Latour o De la Cadena ocultaban su legitimación como una ontología global. En contraposición, la diferencia, podría pensarse de modo afirmativo, como indica Deleuze (2002), al criticar la subordinación de la diferencia al concepto. Es más, para Deleuze la diferencia brota de la misma experiencia y por eso él propone pensar una diferencia no conceptual (Deleuze 1996). De esta manera, se comprende la colisión de la ontología representacional marxista con la ontología relacional indígena presentada por Rivera Cusicanqui, donde la diferencia puede ser entendida sin subordinación a un proceso. Así, la ontología política indígena, entretejida alrededor del Ayllu, fue vista como un obstáculo al desarrollo de la historia. El Ayllu como forma arcaica de vida estaba llamado a desaparecer en el «camino hacia el progreso» (Rivera Cusicanqui 1987: 93). Es precisamente este Ayllu el que fundamenta la democracia comunitaria de los Kitu Kara y en el cual se enraíza la noción de propiedad comunitaria que esperan sea desarrollada desde las ordenanzas municipales de Quito.

El Ayllu como unidad de vida y territorio implica el ejercicio de modos de conocimiento relacionales (no representativos) generando territorialidades no liberales (Escobar 2010). Así, el territorio no es una mera porción de tierras, sino el conjunto relacional de todo lo viviente. Como ha indicado Coulthard (2014), para los Dene de Canadá, el territorio incluye humanos y no humanos como animales, ríos, lagos, montañas y árboles. También Descola (2012) o Viveiros de Castro (2013) señalan la misma sociabilidad relacional entre humanos y no-humanos en el pensamiento amerindio de las culturas amazónicas. Lo que llama la atención en el caso de los Kitu Kara es que, a pesar de los proyectos modernizadores y totalizantes de la ciudad, conserven, actualicen y propongan dicha ontología en un contexto urbano.

Desde aquí que se comprende que Doreen Massey (2004) hable de geografías de la responsabilidad para estas territorialidades no liberales. Es decir, a todo paradigma relacional le sigue la ética de la correspondencia: nos sentimos responsables con todos aquellos con los que estamos conectados. Massey argumenta que las identidades no son la esencialización de cualidades, sino, más bien, el conjunto de flujos y relaciones en los que se desarrolla la vida. Por eso, identidad y relación en el espacio van de la mano, siendo el territorio el resultado de esa relación. Entendemos que la democracia comunitaria (como ejercicio de relaciones) y la propiedad comunitaria (expresión territorial) del Pueblo Kitu Kara son indisociables.

Llegados a este punto nos preguntamos cómo se lleva a cabo este proyecto ontológico en la ciudad de Quito, o dicho en otras palabras, qué expresiones relacionales se dan entre el Pueblo Kitu Kara y el Municipio de Quito, asumiendo que se trata de una diferencia afirmativa en el sentido deleuziano. Históricamente las relaciones con la ciudad han estado profundamente imbricadas en las demandas estatales. El levantamiento indígena de 1990 se realizó desde las plataformas indígenas antes mencionadas, de las que los Kitu Kara hacen parte. Fruto de aquel levantamiento, las constituciones de 1998 y 2008 reconocieron, como vimos, algunas de las demandas planteadas (estado pluricultural y multiétnico en 1998; estado intercultural y plurinacional en 2008). La constitución de 2008 inaugura el neconstitucionalismo andino (Ávila 2016), cuya principal característica es hacer bascular los derechos desde la institución hacia las personas. No obstante, a pesar de introducir estas declaraciones constitucionales no ha sido posible el pleno ejercicio de las mismas. Por ejemplo, la plurinacionalidad, la democracia comunitaria, la autodeterminación y los derechos colectivos siguen siendo asuntos pendientes debido a la falta de articulado de 2 ㅇ y 3 으o orden que permita un ejercicio real desde las comunidades indígenas. Ejemplo de ello es la vigencia de la ley de comunas de 1937 que impide ejercer la autodeterminación y la plurinacionalidad. Además, la década de la revolución ciudadana del Estado ecuatoriano (2007-2017) ha generado conflictos y desencuentros con movimientos sociales y comunidades indígenas al tratar de implementar una agenda desarrollista en clara oposición a los sistemas de vida indígena (Lalander y Ospina 2012).

Por ello, el Pueblo Kitu Kara ha entendido el ejercicio de resistencia y reinterpretación del articulado constitucional desde su propia ontología relacional:

«Resistencia desde la movilización y propuestas, pero también desde la reinterpretación y aplicación de los derechos desde nuestras propias concepciones, cosmovisiones y prácticas en diálogo o confrontación con las propuestas que empezaban en adversidad, a ser visibles y disponibles. Una de ellas, la democracia». (Ana Lucía Tasiguano, Foro Universidad Andina abril 2018) 
A nivel local, la resistencia de los Kitu Kara ha implicado la oposición directa a proyectos específicos impulsados desde el Municipio como la ubicación de un vertedero de basura en Jalonguilla (parroquia de Calderón -norte de Quito-) o la construcción de la vía al nuevo Aeropuerto atravesando los terrenos comunitarios de la comuna de Llano Grande. A ello se suman momentos de tensión por los intentos desde el Municipio de dividir a las comunas y comunidades. Fernando Cabascango indica:

«Hubo una experiencia negativa con la Alcaldía de Barrera, cuando hubo intentos por generar federaciones de comunas paralelas, se cooptó a algunas comunas, esto nos puso en graves conflictos con el pueblo. Finalmente fue un proyecto ambicioso en donde invirtieron muchos recursos, hicieron una federación de comunas de Pichincha, pero no lograron tener respaldo». (Fernando Cabascango, entrevista personal, 16 julio 2018)

No obstante, a pesar de lo afirmado hasta ahora, la negociación es un aspecto clave de la relación de los Kitu Kara con las autoridades estatales y municipales. Ash Amin (2002) entiende la comunidad y lo comunitario como el haz de relaciones en los que surge la identidad, de tal forma que comunidad no es ni algo preconcebido ni una meta a conseguir, sino un lugar de negociación, en el sentido más amplio del término. Teodoro Bustamante, en relación con las comunas y la trabazón entre lo rural y lo urbano afirma que «se debe realizar una negociación entre lo urbano y lo comunal en la cual la comuna podría optar por revalorizar su propia ruralidad, en su nueva inserción urbana» (1992: 26). La negociación, como extensión de la ontología relacional, es un elemento clave de los Kitu Kara, quienes, sin renunciar a la modernidad, se presentan como una alternativa a la ontología de la distribución representacional. Como indica Marisol De la Cadena, los quechuas (y los Kitu Kara lo son) «están conectados con la modernidad sin ser contenidos en los requerimientos epistémicos de la representación» (2015: 100).

Por eso, desde el año 2015, el Pueblo Kitu Kara decidió declarase en diálogo con el Municipio de Quito, siendo reconocida de su Agenda Política, la cual viene de un proceso de reflexión llevado a cabo por los cabildos y consejos de gobierno de las comunas y comunidades desde el año 2014. En ese año se celebró el cuarto Congreso del Pueblo Kitu Kara, se eligió al nuevo Consejo de gobierno y se resolvió construir una
Agenda Política propia a ser presentada a las autoridades del Distrito Metropolitano de Quito. El proceso implicó intercambios y diálogos con las comunas y comunidades con el fin de analizar las problemáticas e identificar demandas y propuestas de políticas públicas frente al Municipio de Quito. Paralelamente a este proceso, en el 2015 el Municipio inicia el primer debate del Proyecto de Ordenanza AIER Ilaló Lumbisí, sin el conocimiento de las comunas y comunidades involucradas, incumpliendo el derecho a la consulta pre-legislativa reconocido en la Constitución del Ecuador. En ese momento el Pueblo Kitu Kara exigió al Municipio el archivo de dicha ordenanza. A partir de ese momento se inician mesas de trabajo con las comunas y comunidades para debatir sobre temas prioritarios relacionados con la autoridad, propiedad y ambiente.

El Pueblo Kitu Kara ha entendido que el mero enfrentamiento no basta para el acercamiento de ontologías. Como indica Costa el acto de traducción implica una interrelación entre la identidad y la alteridad, «haciendo del acto de traducción un proceso de continua dislocación» (2013: 79). Entendemos así que el Pueblo Kitu Kara buscara el acercamiento con las autoridades del Municipio. En el año 2016, tras reunión con el alcalde de Quito se decide conformar cuatro mesas de diálogo político entre autoridades municipales y autoridades comunales y comunitarias: a) mesa de tierras, territorio y ambiente; $b$ ) mesa de gobiernos comunitarios; c) mesa de cultura, identidad y medios de vida; y d) mesa de participación social, política y comunitaria (Pueblo Kitu Kara 2016).

El proceso de las mesas de diálogo incluyó tres momentos: (i) uno de diseño de un documento con objetivos, instrumentos de investigación y normativa jurídica, (ii) un segundo momento de visitas a las comunidades para recoger información de casos y problemáticas puntuales y (iii) un tercer momento en donde se buscó articular los hallazgos con los instrumentos nacionales e internacionales de protección de los derechos indígenas y acordar lineamientos de políticas públicas y generar la Agenda Política del Pueblo Kitu Kara. En 2016 la Agenda fue entregada formalmente al Alcalde y autoridades del Municipio del Distrito Metropolitano de Quito, estableciendo siete ejes de acción: (i) Modelo de Propiedad; (ii) Modelo Ambiental; (iii) Modelo Cultural, Intercultural y Plurinacional; (iv) Modelo de Autoridad y Relacionamiento; (v) Modelo de Planificación; (vi) Modelo de Participación; y, (vii) Legislación y Administración de Justicia. 
En la actualidad, uno de los avances más importantes en términos de incidencia de la agenda ha sido el reconocimiento de la categoría de propiedad comunitaria dentro del Municipio de Quito. Sin embargo el hecho de que no se haya diseñado la ordenanza municipal evidencia que, a pesar de los encuentros y las reuniones, los técnicos y directivos municipales, seguían en el marco epistémico apuntado por García Canclini: «concebir la ciudad como lo que no es el campo» (1997: 69). Como indica el comunero y antropólogo Freddy Simbaña: «Las comunas están resignificándose, pero el Estado no, sigue siendo el mismo. Todavía hay clasismo, racismo. Las comunas han desarrollado niveles de participación y organización, el Estado no» (Entrevista personal, 18 junio 2018).

El ofrecimiento de Jaime Paucar para toda la sociedad ecuatoriana se comprende mejor en el contexto de relaciones que hemos descrito. Paucar entendía que el ejercicio comunitario de la política no era sólo un asunto indígena, sino que podría beneficiar a toda la sociedad. Por ello, ofrecía la experiencia de su comunidad como ejemplo de tal implementación. Así, conscientes del abordaje comunitario desde su propia ontología relacional, el Pueblo Kitu Kara extiende el Ayllu al conjunto municipal, aún con las limitaciones que conlleva enfrentar la episteme de la representación. Podríamos indicar con Cristina Rojas que el proyecto político de los Kitu Kara en la ciudad de Quito está pidiendo «subjetividades capaces de desligarse del capitalismo y en su lugar desear y crear mundos diversos. Estas subjetividades se potencian a través de proyectos colectivos de solidaridad, nuevas formas de sociabilidad y visiones alternativas de felicidad» (Rojas 2007: 585).

\section{CONCLUSIÓN}

A lo largo de este artículo hemos tratado de mostrar el lugar de lo político en el Pueblo Kitu Kara y su articulación con las formas de poder del estado ecuatoriano y del Municipio de Quito. Como indígenas urbanos, los Kitu Kara no sólo han procurado mostrar formas políticas alternativas al municipio, sino que han iniciado un proceso de reflexión auto-identitaria para evidenciar que su ontología política podría funcionar como alternativa a las dinámicas de la ciudad. La articulación de lo político en varios órganos de decisión (Asamblea, Congreso, Consejo de Gobierno) en el Pueblo Kitu Kara impediría, en consonancia con Clas- tres (2014), entender lo político como poder coercitivo y descubrirlo más bien como ejercicio relacional. Hemos procurado iniciar la reflexión desde el testimonio y experiencia de los miembros del pueblo Kitu Kara para, de alguna manera, «no utilizar Occidente como punto de partida» (Gledhill 2000: 26). Si bien es cierto que hemos movilizado ciertas herramientas conceptuales analíticas de carácter occidental, han sido utilizadas en línea con la reflexión autocrítica de los intelectuales del Pueblo Kitu Kara. Por ello, el carácter descriptivo de nuestro trabajo se alinea con el talante crítico de la antropología política que, desprovista del carácter sistemático o normativo, muestra su fortaleza (Lewellen 2009) recortando figuras de lo político sobre un fondo de prácticas sociales (Cañedo y Marquina 2011). Al extender la práctica relacional desde sus propias comunidades al municipio de Quito, el Pueblo Kitu Kara estaría cuestionando que el sentido de lo político pueda darse en realizaciones unilocales y por eso mantiene abierta la posibilidad de construcción de mundos comunes.

\section{BIBLIOGRAFÍA CITADA}

Amin, Ash. 2002. "Ethnicity and the multicultural city: living with diversity». Environment and Planning A 34: 959-980.

Andrade, Gustavo. 2016. Las comunas ancestrales de Quito: retos y desafíos en la planificación. Quito: Universidad Andina Simón Bolívar.

Anghie, Antony. 1996. «Francisco De Vitoria and the Colonial Origins of International Law». Social and Legal Studies 5(3): 321-36.

Ávila, Ramiro. 2016. El neoconstitucionalismo andino. Quito: Universidad Andina Simón Bolivar.

Bigo, Didier. y Walker. R. B. J. 2007. «Political Sociology and the Problem of the International». Millennium: Journal of International Studies 35(3): 725-39.

Biset, Emmanuel. 2011. "Ontología de la diferencia», en Biset, Emmanuel y Farrán, Roque (eds.). Ontologías políticas: 9-42. Buenos Aires: Imago Mundi.

Blaser, Mario. 2013. "Ontological Conflicts and the Stories of People in Spite of Europe: Towards a Conversation on Political Ontology". Current Anthropology 54(5): 547-568.

Blaser, Mario. 2010. Storytelling Globalization from the Chaco and Beyond Durham: Duke University Press.

Bustamante, Teodoro et. al. 1992. Quito: comunas y parroquias. Quito: Fraga.

Cabascango, Fernando. 2019. "Las comunas y comunidades son territorios con continuidad histórica», en Cabascango, Fernando, Corral, Pablo et al. (eds.) Kitu Kara. Quito: Secretaría de Cultura. Ed. Paradocs. 
Cañedo, Montserrat y Marquina Aurora (eds). 2011. Antropología política. Temas contemporáneos. Barcelona: Bellaterra.

Carrera Segundo y Salomon Frank. 2007. Historia, cultura y música ancestral de Zámbiza. Quito: edit. Municipio del Distrito Metropolitano de Quito.

Celestino, Olinda. 1998. "Transformaciones religiosas en los Andes 2. Evangelizaciones». Gazeta de Antropología, 14: $1-22$.

Clastres, Pierre. 2014. La sociedad contra el estado. Barcelona: virus.

Convenio 169 de la Organización Internacional del Trabajo, 01 de febrero de 2014, en <http://www.oit.org.pe/WDMS/bib/ publ/libros/convenio_169_07.pdf>.

Corte Interamericana de Derechos Humanos. 2006. Caso indigena Sawhoyamasca vs. Paraguay, 2006.

Corte Interamericana de Derechos Humanos. 2001. Caso de la Comunidad Mayagna (Sumo) AwasTingni vs. Nicaragua; Fondo, Reparación y Costas; Sentencia de 31 de agosto de 2001; Serie C Nro. 79.

Coulthard, Glen Sean. 2014. Red Skins, White Masks. Minneapolis: University of Minnesota Press.

Costa, Claudia. 2013. «Equivocation, Translation, and Performative Intersectionality: Notes on Decolonial Feminist Practices and Ethics in Latin America.» Revista Anglo Saxonica 3 (6) : 75-98

De la Cadena, Marisol. 2015. Earth Beings: Ecologies of Practice across Andean Worlds. Durham, NC: Duke University Press.

Deleuze, Gilles. 2002. Diferencia y repetición. Buenos Aires: Amorrortu.

Deleuze. Gilles. 1996. Empirismo y subjetividad. Barcelona: Gedisa.

Demon, Jos. 2012. "Una comunidad de migrantes indígenas en la ciudad de Quito: características sociales y laborales», en Erazo, Jaime (Coord.) Políticas de empleo y vivienda en Sudamérica. Quito: Flacso.

Descola, Philippe. 2012. Más allá de Naturaleza y Cultura. Buenos Aires: Amorrortu.

De Velasco, Juan. 1927 [1789] Historia del Reino de Quito en la América Meridional. Quito: Imprenta Nacional

Escobar, Arturo. 2010. «Latin America at the Crossroads: Alternative Modernizations, Postliberalism, or Postdevelopment?». Cultural Studies 24(1): 1-65.

Escobar, Arturo. 2015. «Territorios de diferencia: la ontología política de los derechos al territorio». Desenvolv. Meio Ambiente 35: 89-100. doi: 10.5380/dma.v35i0.43541.

Espín, María Augusta. 2009. La representación indígena en la ciudad: la construcción del indígena urbano en el barrio de San Roque, Tesis de Maestría (FLACSO).

García Canclini, Nestor. 1997. Imaginarios urbanos. Buenos Aires: Editorial Universitaria de Buenos Aires.

Gledhill, John. 2000. El poder y sus disfraces. Perspectivas antropológicas de la política. Barcelona: Bellaterra.
González Suárez, Federico. 1915. Notas arqueológicas. Quito: Imprenta del clero.

Guevara Corral, Rubén D. 2004. «Desplazamiento indígena, conflicto interno y expresiones de participación comunitaria en el departamento del Cauca (Colombia)». HAOL 3: 65-72.

Guevara Ordoñez, Nadia. 2017. «La incorporación de lo indígena en el espacio urbano paceño a principios del siglo XX». Territorios, (36): 69-86. Doi: <http://dx.doi.org/10.12804/ revistas.urosario.edu.co/territorios/a.5093>.

Icaza, Rosalba. y Vázquez Rolando. 2013. «Social Struggles as Epistemic Struggles». Development and Change 44(3): 683-704.

INEC. 2010. Instituto Nacional de Estadísticas y Censos- INEC. Censo Nacional de Población y Vivienda 2010.

ENEMDU. 2012. Instituto Nacional de Estadísticas y Censos. Encuesta Nacional de Empleo y Desempleo 2012.

Jijón y Caamaño, Jacinto. 1998. El Ecuador interandino y occidental antes de la conquista castellana, Vol 1- 5. Quito: Abya-Yala.

Jiménez de la Espada, Marcos (comp.). 1965. «Descripción y Relación del Estado Eclesiástico del Obispado de San Francisco de Quito", en Relaciones Geográficas de Indias, III, Madrid: BAE

Kingman, Eduardo (comp.). 1992. Ciudades de los Andes, visión histórica y contemporánea. Quito: IFEA / Ciudad.

Kingman, Eduardo. 2008. La ciudad y los otros. Quito 18601940, Quito: FLACSO/Fonsal.

Knapp, Gregory y Roy Ryder. 1983. "Aspects of the origin, morphology and function of ridged fields in the Quito altiplano, Ecuador", en Darch J.P (ed) Drained Field Agriculture in Central abnd South America, $44^{\circ}$ International Congress of Americanist, Manchester 1982: 201- 220.

Konetzke, Richard. 1953. Colección de Documentos para la Historia de la Formación Social de Hispanoamérica. 1493-1810, vol. I (1493-1592). Madrid: C.S.I.C

Lalander, Rickard y Ospina, Pablo. 2012. «Movimiento indígena y revolución ciudadana en Ecuador». Cuestiones Políticas 28(48): 13-50.

Latour, Bruno. 1993. We Have Never Been Modern. Cambridge, MA: Harvard University Press.

Lewellen, Ted. 2009. Introducción a la antropología política. Barcelona: Bellaterra.

Macas, Luis. 1990. Indios: Una reflexión sobre el levantamiento indígena de 1990. Quito: ILDIS, Abya Yala.

Massey, Doreen. 2004. "Geographies of responsibility». Geografiska Annaler, vol. 86B, no. 1: 5 -18.

Mol, Annemarie. 1999. "Ontological Politics. A Word and Some Questions». The Sociological Review, 47 (1_suppl): 74-89. https://doi:10.1111/j.1467-954x.1999.tb03483.x

Molina Echeverri, Hernán. 2012. «La población indígena y las ciudades». En <http://observatorioetnicocecoin.org.co/cecoin/index.php?option=com_content \&view=category \&layout=blog\&id=45\&Itemid=103> 
Molina Echeverri, Hernán. 2007. «Nuevos escenarios de vida indígena urbana: El caso de Bogotá». Etnias y política 4: 100-115.

Ordenanza que aprueba el Plan Metropolitano de Ordenamiento Territorial del Distrito Metropolitano de Quito, publicada en el Registro Oficial EE 274 de 29 de marzo de 2012.

Organización de los Estados Americanos. 2012. Derechos de los Pueblos Indígenas y Tribales sobre sus Tierras Ancestrales y Recursos Naturales; 01 de febrero de 2014; en http://www.cidh.org.

Pacari, Nina. 2019. "Reflexiones sobre territorios indígenas e interculturales en estados plurinacionales". En Cabascango, F., Corral, P. et alt (eds.) Kitu Kara. Quito: Secretaría de Cultura. Ed. Paradocs.

Plata Juan José. 2000. «Etnografías urbanas en mundos globalizados: aspectos conceptuales y metodológicos» en Mejía Germán. y Zambrano Fabio. (eds.). La ciudad y las ciencias sociales. Bogotá: Instituto Distrital de Cultura y Turismo, Centro Editorial Javeriano.

Poirier, Sylvie. 2008. «Reflections on Indigenous Cosmopolitics - Poetics». Anthropologica 50 (1): 75-85.

Portal, Ana María. 2013. «El desarrollo urbano y su impacto en los pueblos originarios en la Ciudad de México». Alteridades 23(46): 53-64.

«Probanza de Méritos de Don Pedro de Zámbiza, cacique de Zámbiza y Alcalde Mayor de Naturales». Archivo General de Indias/Sevilla. Audiencia de Quito 26.

Pueblo Kitu Kara 2016. Agenda Política del Pueblo Kitu Kara.

Quijada Jara, Sergio. 1981. Estampas Huancavelicanas. Lima: Dugrafis S.R.L.

República del Ecuador. Constitución de 20 de octubre de 2008.

República del Ecuador. Constitución de 11 de agosto de 1998.

República del Ecuador. Ley de Organización y Régimen de Comunas. Codificación 4. Registro Oficial Suplemento 315 de $16-a b r-2004$

República del Ecuador. Ley Orgánica de Tierras y Territorios de 2012.

República del Ecuador. Ley Orgánica de Tierras Rurales y Territorios Ancestrales. Oficio no. san-2016-0398 Quito, 07 mar 2016.

Rivera Cusicanqui, Silvia. 1990. «Democracia liberal y democracia de ayllu: El caso del Norte Potosi', Bolivia», en Roca C. F. Toranzo (ed.) El Difícil Camino Hacia la Democracia: 9-51. La Paz: ILDIS.

Rivera Cusicanqui, Silvia. 1987. Oppressed but Not Defeated: Peasant Struggles among the Aymara and Qhechwa in Bolivia, 1900-1980. Geneva: United Nations Research Institute for Social Development.

Rojas, Cristina. 2016. «Contesting the Colonial Logics of the International: Toward a Relational Politics for the Pluriverse». International Political Sociology 10 (4): 369-382. <https:// doi.org/10.1093/ips/olw020>

Rojas, Cristina. 2007. «International Political Economy/Development Otherwise». Globalizations 4 (4): 573-87
Rojas, Cristina. 2002. Civilization and Violence: Regimes of Representation in 19th-Century Colombia. Minneapolis: University of Minnesota Press.

Salomon, Frank. 2011. Los señores étnicos de Quito en la época de los incas. La economía política de los señores étnicos norandinos. [2ª edición, corregida y aumentada]. Quito: Instituto Metropolitano de Patrimonio.

Salomon, Frank. y Grosboll, Sue. 1986. «Names and Peoples in Incaic Quito: Retrieving Undocumented Historic Processes Through Anthroponymy and Statistics" American Anthropologist. New Series 88(2): 387-399.

Scott, James. 1998. Seeing like a State. New Haven and London: Yale University Press.

Seth, Sanjay. 2013. "'Once Was Blind but Now I Can See’: Modernity and the Social Sciences». International Political Sociology 7(2): 136-51.

Simbaña, Freddy. E. 2018. "El barrio y la calle, otro espacio de exclusión social. Caso indígenas urbanos en la ciudad de Quito". En Jorge E. Horbath y María Amalia Gracia (eds.). La cuestión indígenas en las ciudades de las Américas. Procesos, políticas e identidades: 231-254. Buenos Aires: Clacso y Miño y Dávila editores.

Spivak, Gayatri. 1988. "Subaltern Studies: deconstructing historiography», en Guha, Ranajit y Spivak, Gayatri. (eds.) Selected Subaltern Studies. Nueva York: Oxford University Press.

Spivak, Gayatri. 1994. "Can the subaltern speak?», en Patrick Williams y Laura Chrisman (eds.) Colonial Discurse and Post-colonial Theory: a reader. Nueva York: Columbia University Press.

Tasiguano, Ana Lucía. 2011. Transformaciones y desafíos del gobierno comunitario Kitu Kara, estudio de casos: Comuna Cocotog, Lumbisí y la Tola Chica. Tesis inédita de maestría Universidad Autónoma Indígena Intercultural UAIIN. Popayán.

Terán Najas, Rosemarie. 1992. "La ciudad colonial y sus símbolos: Una aproximación a la historia de Quito en el siglo XVII», en Kingman E. (comp.) Ciudades de los Andes, visión histórica y contemporánea: 93-103. Quito: IFEA / Ciudad.

Urteaga, Maritza. 2007. "Jóvenes e indios en la ciudad». Tramas 18: 85-120.

Valarezo, Galo. R. 1992. "Quito aborigen: un balance de sus interpretaciones», en Peralta, E., Carrión F. et alt. (eds.) Enfoques y estudios históricos. Quito a través de la historia. Quito: Junta de Andalucía.

Vera Parra, Dayan D. 2015. "Los cabildos urbanos y su incidencia en la deslegitimación de las colectividades de los pueblos originarios». Revista Kénosis, 3: 28-41.

Viveiros de Castro, Enrique. 2013. La mirada del jaguar. Introducción al perspectivismo amerindio. Buenos Aires. Amorrortu.

Yampara, S. 2001. El ayllu y la territorialidad en los Andes: Una aproximación a Chamba Grande. La Paz: Universidad Pública de El Alto. 